\title{
Predictors of Stunting among School-Age Children in Northwestern Ethiopia
}

\author{
Amare Lisanu Mazengia $\left.{ }^{1}\right)^{1}$ and Gashaw Andargie Biks $\mathbb{D D}^{2}$ \\ ${ }^{1}$ College of Health Sciences, Salale University, Fiche, Ethiopia \\ ${ }^{2}$ College of Health Sciences and Medicine, Gondar University, Gondar, Ethiopia \\ Correspondence should be addressed to Amare Lisanu Mazengia; amarelm21@yahoo.com
}

Received 13 June 2018; Revised 17 July 2018; Accepted 14 August 2018; Published 20 September 2018

Academic Editor: Pei Jiang

Copyright ( 2018 Amare Lisanu Mazengia and Gashaw Andargie Biks. This is an open access article distributed under the Creative Commons Attribution License, which permits unrestricted use, distribution, and reproduction in any medium, provided the original work is properly cited.

\begin{abstract}
Background. Stunting is a major public health problem in most developing countries, and it increases the risk of illness and death throughout childhood. It is also a major public health problem in Ethiopia. Most of the few studies done in Ethiopia were done in schools. However, the prevalence of stunting of school-age children at the community level is largely unknown. Objective. To assess prevalence and predictors of stunting among school-age children in Mecha District, Amhara Regional State, Ethiopia. Methods. A community-based cross-sectional study was conducted from August 28, 2017, to October 10, 2017. Target population for the study was school-age children (children of age 5-15). A total of 802 children were included in the study. The multistage sampling procedure was applied. Data were collected through face-to-face interview using the structured questionnaire. Anthropometric measurement was performed and analyzed using ENA SMART software. Association was assessed using logistic regression (backward LR). Statistical significance was measured using adjusted odds ratio at 95\% CI and $P$ value less than 0.05 . Results. About 37.9\%, with 95\% CI $(34.6,41.3)$, of children were stunted. The predictors of stunting were child age with AOR (95\% CI) $1.4(1.02,1.91)$, family size with AOR $(95 \%$ CI) 1.83 (1.21, 2.75), mother's education with AOR (95\% CI) 1.81 (1.01, 3.24), father's occupation with AOR (95\% CI) 5.23 (1.55, 17.64), and child's immunization status with AOR (95\% CI) 5.6 (2.90, 10.82). Conclusion. Stunting is still an important problem among children in the age of 5-15 years. Therefore, special attention should be given to child's full immunization, limiting of family size, continued promotion of female education, and appropriate feeding practice of children depending on their age.
\end{abstract}

\section{Background}

Malnutrition continues to be a major public health problem in developing countries [1]. It is the most important risk factor for the burden of disease directly and indirectly responsible for more than half of all deaths in children [1-3]. About $53 \%$ of child deaths are attributable to malnutrition in the world [4]. Stunting is one form of malnutrition, and children whose height-for-age $Z$-score is below $-2 \mathrm{SD}$ from the median of WHO reference population are considered short for their age (stunted). Children who are below $-3 \mathrm{SD}$ are considered severely stunted $[5,6]$.

Stunting reveals miscarriage to obtain sufficient amount and quantity of nutrition over a long period of time and is influenced by environmental factors, socioeconomic circumstances, and recurrent and chronic illness [6]. Therefore, stunting represents the long-standing effects of nutritional problems in the community and is not sensitive to recent, short-term deviations of dietary intake [7]. Stunting leads to $14.5 \%$ of deaths yearly and $12.6 \%$ of infirmity adjusted life-years [8]. Stunting decreases future school achievements and revenue as adults, and it raises the threat of obesity and noncommunicable diseases [9].

Globally, the estimated number of stunted under-five children is 165 million [10]. More than 200 million schoolage children were stunted by the year 2000 , and the proportion of stunted school-age children with impaired physical and mental development is expected to grow up to 1 billion by the year 2020 unless a tangible action is undertaken [11]. 
About 25\% of African elementary schoolchildren were found below the fifth centile of the United States-National Center for Health Statistics (US-NCHS) reference for height-for-age $Z$-score (HAZ) [12]. In Ethiopia, 40 percent of under-five children are stunted, and 18 percent of children are severely stunted. In the Amhara region, 42 percent of under-five children are stunted [13]. Even though stunting has serious consequences on morbidity and mortality of children, limited attention has been given [14], and cautious attention of stunting indicator is an important part of policy discussions on community nutrition programs [15]. Stunting is not considered in school-age children in many parts of the world including Ethiopia, and little is known about the occurrence of stunting in this age group. Therefore, to develop effective interventions and to decrease stunting in this age group of children, a sound understanding on the magnitude and predictors of stunting is essential.

\section{Methods}

2.1. Study Design Area and Period. A quantitative community-based cross-sectional study was conducted to assess prevalence and predictors of stunting among schoolage children. This study was conducted at the Mecha district from August 28, 2017, to October 10, 2017. The Mecha district is located $529 \mathrm{~km}$ northwest away from the capital, Addis Ababa, and it is situated at an altitude ranging from $1800 \mathrm{~m}$ to $2500 \mathrm{~m}$. The district receives an average annual rainfall ranging from $1000 \mathrm{~mm}$ to $2000 \mathrm{~mm}$ and average daily temperature from $17^{\circ} \mathrm{C}$ to $30^{\circ} \mathrm{C}$. The total population of the district was about 370032 ; of these, 80727 (21.8\%) were in the age of 5-15 years [16].

\subsection{Source Population and Sample Size Determination.} The source population was all children from the age of 5-15 years who live in the Mecha district, and the study population was all children from the age of 5-15 years who live in the selected kebeles. Sample size was determined by using a single population proportion formula with the assumptions of $95 \%$ CI, 5\% of margin of error, reported prevalence of stunting in school-age children $P(48.1 \%)$ [17], design effect 2 , and $5 \%$ possible nonresponse rate, which gives the total sample size of 802 .

2.3. Inclusion and Exclusion Criteria. All children aged between 5 and 15 years who live in the district were included in the study. Children who had anatomical deformity, seriously ill children during data collection, and children whose age was not known were excluded.

2.4. Sampling Technique. The multistage simple random sampling procedure was used with the strata of kebeles which exist in semiurban and rural. A total of 46 kebeles are in the district (40 rural andand 6 semiurban). At the first stage, due to resource constraints, $20 \%$ of the kebeles ( 8 rural and 1 semiurban kebeles proportionally) were selected by using the simple random sampling technique. Then, the total sample was allocated proportionally to the study population size of each kebele. By using family folder lists (CHIS Household ID) of the health extension program, the sampling frame was prepared, the simple random sampling technique was applied, and then participants from each kebele were identified by using the computer randomized method.

\subsection{Variables of the Study}

2.5.1. Dependent Variable. Children with $Z$-score less than -2 (height for age $<-2$ ) were categorized as stunted, whereas those with $Z$-score -2 and above were categorized as normal as per the 2007 WHO Z-score standard.

2.5.2. Independent Variables. Sociodemographic variables: marital status, educational status, occupation, place of residence (being rural or semiurban), family size, and household assets. Child characteristics: age, sex, height, gestational age during birth, exclusive breastfeeding status, and morbidity status. Child-caring practices: hygiene, feeding, health care seeking, and immunization. Maternal characteristics: total number of children and sovereignty in decisionmaking on use of resources. Environmental health condition: availability of latrine, water supply, sanitation, and housing condition.

2.6. Data Collection and Quality Control. Data were collected using a pretested structured questionnaire by face-to-face interview. The interviews were conducted by six freshly graduated trained clinical nurses supervised by two health officers. Standard UNICEF-aided fixed board meters were used to measure the height of the children. Measurement of height was taken to the nearest $0.1 \mathrm{~cm}$ with the children barefooted. Data collectors and supervisors were trained on the use of the fixed board meters prior to the fieldwork.

The age of children was collected in months, and if the mother could not remember child's age, local events were used to assist the mother. Supervisors and principal investigator (PI) checked the accuracy and completeness of the data that were collected daily. Any error in data collection was corrected before proceeding with the next day's data collection activity. The interview was conducted in a place where the participants felt free to express themselves. To assure the data quality, one-day training was given to the data collectors as well as the supervisors concerning the objectives of the study, ways of the interview, the questionnaire, and how to measure each child's height with demonstration. The data collection tool was pretested prior to the real data collection on 40 participants (5\% of the sample), in a place other than the study area. This was a good chance to make changes in the questionnaire which was difficult to understand during the interview. Throughout the progression of data collection, data collectors were overseen at each site of data collection place, and daily meetings were conducted between the data collectors and the principal 
investigator in such a way that problematic issues faced during the interview were discussed and decisions were reached. One additional visit was done for respondents who were not found in the first visit. The gathered data were revised and verified for completeness prior to data entry; the incomplete data were excluded.

2.7. Data Processing and Analysis. The complete data were coded and entered into Epi Info (version 3.5.1), and they were exported to SPSS version 20 for analysis. Anthropometric data were analyzed using ENA SMART software in terms of the WHO standard, and the wealth index was analyzed using Stata (version 12). Data cleaning was made manually to exclude subjects with incomplete data. Reliability of the cleaned data was checked through Cronbach's alpha, and its value is 0.71 which is greater than the cutoff point. The final data file was compiled for analysis. During the analysis, frequencies of different variables were determined, followed by cross-tabulation to compare the frequencies. Binary logistic regression analysis was done to measure the crude association between each independent variable through dependent variable, and variables having $P$ value $<0.2$ were included in multivariable logistic regression analysis. The Hosmer and Lemeshow test for model fitness was checked in multivariable logistic regression, and it is 0.94 which is much greater than the cutoff point. $P$ value $<0.05$ was used as a cutoff point for statistical significance of the study.

2.8. Ethical Approval. The proposal was reviewed and approved by the Research and Ethics Committee of the University of Gondar. The district health office was informed by an official letter from the University of Gondar, and permission to undertake this study was obtained from the concerned authorities. Then, participants were informed about the importance of the study, necessity of their contribution, risk, and discontinuation at any time, and written consent and assent were obtained before the data collection. Confidentiality of data given by each participant was maintained. After completing the interview, acknowledgment was given to the participants, and seriously ill individuals were referred to the nearest health institutions.

\subsection{Operational Definitions}

Stunting: children who have height for age below -2 SD of the median of the standard curve (WHO reference population).

School-age children: children in the age of 5-15 years. Timely started complementary food: diets which are essential to the child and started at six months of age. Wealth index (WI): It is a merged index collected of important asset possession variables used as a representation indicator of the family level of wealth [18].

\section{Results}

3.1. Sociodemographic Characteristics. From all 802 participants included in this study, 800 (99.75\%) delivered complete response. Altogether, 728 (91\%) of households were headed by males who were married. Majority (733: $91.6 \%)$ of respondents lived in rural areas. Out of the respondents, $597(74.6 \%)$ of households had more than national average family size which is greater than or equal to five. Concerning educational status, 664 (83\%) of mothers and $597(74.6 \%)$ of fathers were illiterate (could not read and write). Around 690 (86.3\%) of mothers and 677 (84.7\%) of fathers were farmers. About 544 (68\%) of both husband and wife decided equally on use of household resources. Concerning livestock, 713 (89.1\%) of families had livestock and $691(86.4 \%)$ of households had farm land, and from these, $584(73 \%)$ had $>0.5$ hectare (Table 1$)$.

3.2. Children Characteristics and Caring Practices. Among the total children, $458(57.2 \%)$ were in the age of $60-120$ months and $342(42.8 \%)$ were in the age of 121-180 months, and $419(52.4 \%)$ of the total participants were males. The mean age and SD of school-age children in the current study were 115.3 and 32.5, respectively. About 19 (2.4\%) of children were born after less than nine months of gestation. Regarding complementary feeding practices, only 394 (49.3\%) were started appropriately at six months. The most frequent child-feeding practice was three times per day (471 (58.9\%); Table 2).

3.3. Environmental Health Characteristics of Households. Regarding treatment of water, about 771(96.4\%) of HHs did not treat water by any means for their family consumption. Most family units (711 (88.9\%)) had la- 6trines, and 499 (62.4\%) of families used only water for handwashing after toilet. About the waste disposal system, 476(59.5\%) households disposed their garbage in open field,while 236 (29.5\%) used individual pits and/or composts. Themain sources of drinking water in the households wereunprotected sources (474 (59.3\%); spring, well, and riverwater), and 326 (40.7\%) were from protected spring/well andpublic tab (Table 3)

3.4. Stunting/Height-for-Age. From 60 to 180 months, participants (303 (37.9\%); 95\% CI (34.6, 41.3)) were stunted. No significant difference in stunting was identified between boys (159 (19.9\%)) and girls (144 (18\%)) in this study. Children from educated mothers were less likely to be stunted $(22(2.8 \%))$ than those from uneducated mothers (281 (35.1\%)). Severe stunting was observed in 84 (10.5\%; $95 \%$ CI $(8.6,12.8))$ children: the frequency was almost equal in males $(41(5.1 \%))$ and females $(43(5.4 \%))$.

3.5. Factors Associated with Stunting of Children. As presented in Tables 4 and 5, first predictors were assessed through binary logistic regression analysis: of these, twelve variables had significant effects on stunting. Variables that had $P$ value $<0.2$ in binary logistic regression were accepted into multivariable logistic regression analysis. Among these, five predictors were statistically significant $(P<0.05)$. 
TABLE 1: Sociodemographic characteristics of participants at Mecha district, Northwestern Ethiopia, $2017(N=800)$.

\begin{tabular}{lccc}
\hline Variables & Category & Frequency & Percentage \\
\hline \multirow{2}{*}{ Residence } & Rural & 733 & 91.6 \\
& Semiurban & 67 & 8.4 \\
Family size & $\geq 5$ & 597 & 74.6 \\
Mother's & $<5$ & 203 & 25.4 \\
educational level & Illiterate & 664 & 83 \\
Father's & Literate & 136 & 17 \\
educational level & Illiterate & 597 & 74.6 \\
Decision-maker & Literate & 202 & 25.4 \\
on use of money & Mainly wife & 74 & 9.3 \\
& Mainly husband & 182 & 22.7 \\
Marital status & Moth jointly & 544 & 68 \\
of mother & Married & 728 & 91 \\
& Othorced & 47 & 5.9 \\
Mother's & Farmer/housewife & 690 & 3.1 \\
occupation & Merchant & 96.3 & 12 \\
& Governmen't and & 14 & 1.8 \\
Father's & private employee & 677 & 84.6 \\
occupation & Farmer & 75 & 9.4 \\
& Merchant & 48 & 6 \\
\hline
\end{tabular}

${ }^{*}$ Widowed and single.

TABLE 2: Characteristics of school-age children and their mothers' practice to give childcare at Mecha district, Northwestern Ethiopia, $2017(N=800)$.

\begin{tabular}{lccc}
\hline Variable & Category & Frequency & Percentage \\
\hline \multirow{2}{*}{ Sex of child } & Male & 419 & 52.4 \\
& Female & 381 & 47.6 \\
Child's age in months & $60-120$ & 458 & 57.2 \\
Gestational age of child & $121-180$ & 342 & 42.8 \\
during birth & $<9$ months & 19 & 2.4 \\
& $\geq 9$ months & 781 & 97.6 \\
Child's starting age of & $<6$ months & 120 & 15 \\
complementary feeding & $>6$ months & 286 & 35.8 \\
& At 6 months & 394 & 49.2 \\
Fully immunized child & No & 59 & 7.4 \\
& Yes & 741 & 92.6 \\
Age of the mother at & $<19$ years & 16 & 2.5 \\
first birth & $\geq 19$ years & 612 & 97.5 \\
Total number of & $<4$ & 314 & 39.3 \\
children in the family & $\geq 4$ & 486 & 60.7 \\
Family planning used & No & 246 & 30.7 \\
& Yes & 554 & 69.3 \\
Types of family & Short term & 510 & 63.8 \\
planning used & Long term & & \\
& and & 44 & 5.5 \\
\hline
\end{tabular}

\section{Discussion}

The overall prevalence of stunting in the current study was about $38 \%$. This prevalence rate was slightly lower than $40 \%$ which is often cited as the cutoff point for public health significance. It was higher than figures reported in facility-
TABLE 3: Environmental health characteristics of households at Mecha district, Northwestern Ethiopia, $2017(N=800)$.

\begin{tabular}{|c|c|c|c|}
\hline Variable & Category & Frequency & Percentage \\
\hline \multirow{2}{*}{$\begin{array}{l}\text { Do you treat drinking } \\
\text { water by any means }\end{array}$} & No & 771 & 96.4 \\
\hline & Yes & 29 & 3.6 \\
\hline \multirow{3}{*}{ Have you a latrine } & No & 89 & 11.1 \\
\hline & Yes & 711 & 88.9 \\
\hline & Not washed & 53 & 6.6 \\
\hline \multirow{3}{*}{$\begin{array}{l}\text { Hand washing } \\
\text { practice } \\
\text { of child's mother } \\
\text { after toilet }\end{array}$} & Using water only & 499 & 62.4 \\
\hline & $\begin{array}{c}\text { Sometimes using } \\
\text { soap/ash }\end{array}$ & 155 & 19.4 \\
\hline & $\begin{array}{l}\text { Always using } \\
\text { soap/ash }\end{array}$ & 93 & 11.6 \\
\hline \multirow{4}{*}{$\begin{array}{l}\text { Methods of HHs' } \\
\text { waste disposal }\end{array}$} & $\begin{array}{l}\text { Open-field } \\
\text { disposal }\end{array}$ & 476 & 59.5 \\
\hline & $\begin{array}{l}\text { Individual } \\
\text { pit/compost }\end{array}$ & 236 & 29.5 \\
\hline & Common pit & 28 & 3.5 \\
\hline & Burning & 60 & 7.5 \\
\hline
\end{tabular}

based cross-sectional studies conducted worldwide (26\%) [11], eight provinces of Indonesia (28.11\%) [19], Palestine (7.3\%) [20], Baghdad, Iraq (18.7\%) [21], Rongshui County and Dingan County of Southern China (25.6\%) [22], Onda, Bankura District, India (17\%) [23], and Sagamu in Southwestern Nigeria (14.2\%) [24]. The observed variance in rates might be due to differences in study area, socioeconomical, topographical, developmental, cultural, and feeding habits of children.

The prevalence of stunting in the current study was also much higher than that in other studies that were reported in Ethiopia-11.5\% in Horo Guduru Welega, 25.2\% in Dale Woreda, Sidama Zone, and $25.2 \%$ in two randomly selected governmental elementary schools in Gondar town. This difference may have arisen partly from peculiarities of the target populations in the various studies considering that the current study was community-based, while the earlier ones were among schoolchildren. It is conceivable that stunted children were more likely to drop out of school and would remain in the community.

On the contrary, some earlier Ethiopian studies reported rates of stunting comparable to or higher than those found in the current study-39.8\% and $48.1 \%$ from Libo Kemkem and Fogera Woreda [25] and East Gojjam Zone [17], respectively. Also, a study from Indonesia [19] reported a higher rate of $46.5 \%$. Explanations for the differences in rates could lie in cultural, socioeconomical, and geographical factors.

The current study found that the odds of stunting were 1.4 times higher in children above 10 years than in younger subjects. This pattern is similar to earlier findings in Indonesia [19] and other parts of Ethiopia like Dale Woreda [26] and Fogera Woreda and Libo Kemkem [25]. This reflects the nature of stunting as a chronic nutritional problem which develops over a relatively long period of time and which is difficult to reverse once established.

A strong relationship was established in the present study between lack of immunization and stunting. The reasons for this association were not investigated and are 
TABLE 4: Binary logistic regression analysis results in school-age children at Mecha district, Northwestern Ethiopia, $2017(N=800)$.

\begin{tabular}{|c|c|c|c|c|}
\hline Variables & Stunted $(N=303)$ & Nonstunted $(N=497)$ & COR $(95 \% \mathrm{CI})$ & $P$ values \\
\hline \multicolumn{5}{|l|}{ Residence } \\
\hline Rural & 295 & 438 & $4.97(2.34,10.55)$ & $P<0.0001$ \\
\hline Semiurban & 8 & 59 & 1.00 & \\
\hline \multicolumn{5}{|l|}{ Age of children } \\
\hline $121-180$ months & 149 & 193 & $1.52(1.14,2.03)$ & $P=0.004$ \\
\hline $60-120$ months & 154 & 304 & 1.00 & \\
\hline \multicolumn{5}{|l|}{ Fully immunized child } \\
\hline No & 46 & 13 & $6.66(3.54,12.6)$ & $P<0.0001$ \\
\hline Yes & 257 & 484 & 1.00 & \\
\hline \multicolumn{5}{|l|}{ Source of drinking water } \\
\hline Unprotected source & 194 & 280 & $1.4(1.03,1.85)$ & $P=0.032$ \\
\hline Protected source & 109 & 217 & 1.00 & \\
\hline \multicolumn{5}{|c|}{ Hand washing practice of child's mother after toilet } \\
\hline Not washed & 25 & 28 & $2.43(1.20,4.93)$ & $P=0.014$ \\
\hline Using only water & 190 & 309 & $1.67(1.02,2.74)$ & $P=0.041$ \\
\hline Sometimes soap/ash & 63 & 92 & $1.86(1.07,3.26)$ & $P=0.029$ \\
\hline Always soap/ash & 25 & 68 & 1.00 & \\
\hline \multicolumn{5}{|l|}{ Wealth index } \\
\hline Quintile 1 & 56 & 104 & $2.15(1.30,3.57)$ & $P=0.003$ \\
\hline Quintile 2 & 74 & 86 & $3.44(2.10,5.66)$ & $P<0.0001$ \\
\hline Quintile 3 & 70 & 90 & $3.11(1.89,5.12)$ & $P<0.0001$ \\
\hline Quintile 4 & 71 & 89 & $3.19(1.94,5.25)$ & $P<0.0001$ \\
\hline Quintile 5 & 32 & 128 & 1.00 & \\
\hline \multicolumn{5}{|l|}{ Family size } \\
\hline$\geq 5$ & 249 & 338 & $2.17(1.53,3.08)$ & $P<0.0001$ \\
\hline$<5$ & 54 & 159 & 1.00 & \\
\hline \multicolumn{5}{|l|}{ Father's education } \\
\hline Illiterate & 242 & 355 & $1.59(1.13,2.23)$ & $P=0.008$ \\
\hline Literate & 61 & 142 & 1.00 & \\
\hline \multicolumn{5}{|l|}{ Mother's education } \\
\hline Illiterate & 281 & 383 & $3.80(2.35,6.15)$ & $P<0.0001$ \\
\hline Literate & 22 & 114 & & \\
\hline \multicolumn{5}{|l|}{ Mother's occupation } \\
\hline Housewife/farmer & 283 & 407 & $9.04(1.18,69.49)$ & $P=0.034$ \\
\hline Merchant & 19 & 77 & $3.21(0.39,26.07) \#$ & $P=0.276$ \\
\hline Govern't and private worker & 1 & 13 & 1.00 & \\
\hline \multicolumn{5}{|l|}{ Father's occupation } \\
\hline Farmer & 290 & 387 & $8.24(2.93,23.20)$ & $P<0.0001$ \\
\hline Merchant & 9 & 66 & $1.50(0.44,5.17)^{\#}$ & $P=0.521$ \\
\hline Government and private worker & 4 & 44 & 1.00 & \\
\hline \multicolumn{5}{|l|}{ Types of FP used } \\
\hline Not used modern FP & 104 & 142 & $3.30(1.47,7.39)$ & $P=0.004$ \\
\hline Short term & 191 & 319 & $2.69(1.23,5.92)$ & $P=0.014$ \\
\hline Long term andand permanent & 8 & 36 & 1.00 & \\
\hline
\end{tabular}

Note. ${ }^{*}$ Not significant in binary logistic regression; COR: crude odds ratio.

more likely to be indirect than direct. It may be argued that poorly vaccinated children are more likely to contract illnesses that may in turn lead to stunting. It is also plausible that the same socioeconomic and cultural factors responsible for stunting may also influence the attitude and practice of parents with respect to child immunization.

In line with findings in Indonesia [19], large family size was found to be strongly associated with stunting. The large family size would imply lower quantity of food available for each family member in comparison with smaller families with the same economic power. Moreover, large family size may also increase the risk of overcrowding that will lead to spreading of diseases such as recurrent acute respiratory infections, malaria, and diarrhea which can lead to malnutrition. Therefore, it is not surprising that stunting occurred more commonly among children from large number families compared to children from small number families.

In this study, illiterate mother was one of the risk factors of stunting. Maternal education has been previously found to be an important risk factor for stunting in Indonesia [19], in Southern China [22], and in Abeokuta, Southwest Nigeria [27]. Educated mother may be more exposed to the media, 
TABLE 5: Predictor variables of multivariable logistic regression analysis in school-age children at Mecha district, Northwestern Ethiopia, $2017(N=800)$.

\begin{tabular}{|c|c|c|c|c|}
\hline Variables & Stunted $(N=303)$ & Nonstunted $(N=497)$ & COR & AOR $(95 \% \mathrm{CI}) ; P$ values \\
\hline \multicolumn{5}{|l|}{ Age of children } \\
\hline $121-180$ months & 149 & 193 & 1.52 & $1.4(1.02,1.91) ; P=0.037$ \\
\hline $60-120$ months & 154 & 304 & 1.00 & \\
\hline \multicolumn{5}{|l|}{ Fully immunized child } \\
\hline No & 46 & 13 & 6.66 & $5.6(2.90,10.82) ; P<0.0001$ \\
\hline Yes & 257 & 484 & 1.00 & \\
\hline \multicolumn{5}{|l|}{ Family size } \\
\hline$\geq 5$ & 249 & 338 & 2.17 & $1.83(1.21,2.75) ; P=0.004$ \\
\hline$<5$ & 54 & 159 & 1.00 & \\
\hline \multicolumn{5}{|l|}{ Mother's education } \\
\hline Illiterate & 281 & 383 & 3.80 & $1.81(1.01,3.24) ; P=0.045$ \\
\hline Literate & 22 & 114 & & \\
\hline \multicolumn{5}{|l|}{ Father's occupation } \\
\hline Farmer & 290 & 387 & 8.24 & $5.23(1.55,17.64) ; P=0.008$ \\
\hline Merchant & 9 & 66 & 1.50 & $1.49(0.42,5.3) ; P=0.5^{* *}$ \\
\hline Government and private worker & 4 & 44 & 1.00 & \\
\hline
\end{tabular}

Note. ${ }^{* *}$ Not significant; COR: crude odds ratio; AOR: adjusted odds ratio.

not illiterate, have higher participation in the labor market, and have better understanding on nutrition and health. She may also have greater authority in the home and can raise productivity to improve their family and child nutritional status. She would also better use the childhood survival strategies, like sufficient breastfeeding, vaccination, and limiting of their family size. As a result, education of girls would be the wise method of reducing the magnitude of stunting.

Paternal occupation was also another significantly associated factor of stunting. This had been reported in an earlier Fincha's sugar estate, an Ethiopian study as well [28]. Moreover, the results of the current study indicate no association between wealth index and stunting. Although the wealth index is taken as a proxy for household assets, the apparently contradictory finding may have resulted from withholding of relevant information on assets and/or father's education.

\section{Conclusion}

The magnitude of stunting in the study area was very high but fell slightly short of the cutoff point for being classified as a public health concern. Occupational status of fathers, educational status of mothers, family size, immunization level, and age of children were significant predictors of stunting in school-age children. These findings suggest the need for strengthening childhood immunization, limiting of family size, improved female education, and appropriate feeding practice of children.

\section{Abbreviations}

EDHS: Ethiopia Demographic and Health Survey

HAZ: Height-for-age $Z$-score

HHs: Households

SRS: $\quad$ Simple random sampling

WHO: World Health Organization.

\section{Data Availability}

The data supporting the findings of this study are available from the corresponding author upon request.

\section{Additional Points}

Limitations of the Study. Participants' might have a memory loss during responding questions that were asked for the past events. Information on some significant variables might not have been collected, and this could have affected interpretation of results. One example is parasitic infestation which is widespread among children. About $92 \%$ of study participants were from rural communities: this limits generalization to urban dwellers. Recommendations. Community: mandatory childhood immunization. Family: limiting of family size to an affordable number, and age-specific attention should be given while childfeeding. Administrators: improved access to childhood immunization and sustainable encouragement of female education. Researchers: further studies should be done exploring other potential associated factors that were not included in the present study especially parasitic infection, anemia, and so on.

\section{Conflicts of Interest}

The authors declare that there are no conflicts of interest regarding the publication of this paper.

\section{Authors' Contributions}

Amare Lisanu Mazengia wrote the proposal, participated in data collection, analyzed the data, and drafted the manuscript. Gashaw Andargie Biks approved the proposal with some revisions, participated in data analysis, and revised subsequent drafts of the paper. 


\section{Acknowledgments}

The authors would like to acknowledge Mecha Woreda Health Department staff for their cooperation during the preparation of the theses, especially giving motorcycle for supervision during data collection, and like to express their deepest gratitude to the participants, supervisors, and data collectors for the fulfillment of the theses.

\section{References}

[1] O. Müller and M. Krawinkel, "Malnutrition and health in developing countries," Canadian Medical Association Journal, vol. 173, no. 3, pp. 279-286, 2005.

[2] L Amy, S Rice, A. Hyder, and R. Blac, "Malnutrition as an underlying cause of childhood deaths associated with infectious diseases in developing countries," Bulletin of the World Health Organization, vol. 78, no. 10, pp. 1207-1221, 2000.

[3] D. L. Pelletier, E. A. Frongillo, D. G. Schroeder, and J. P. Habicht, "The effects of malnutrition on child mortality in developing countries," WHO Bulletin OMS, vol. 73, no. 4, pp. 443-448, 1995.

[4] L. Caulfield, M. Onis, M. Blössner, and R. Black, "Undernutrition as an underlying cause of child deaths associated with diarrhea, pneumonia, malaria, and measles1," American Journal of Clinical Nutrition, vol. 80, no. 1, pp. 193-198, 2004.

[5] WHO, Physical Stat Use, the Use and Interpretation of Anthropometry, World Health Organization, Geneva, Switzerland, 1995.

[6] Central Statistical Agency Addis Ababa E, Ethiopia Demographic and Health Survey 2011, ICF International, Calverton, MD, USA, 2011.

[7] WHO, Catalogue of Health Indicators; A Selection of Important Health Indicators Recommended by WHO Program, WHO, Geneva, Switzerland, 1996.

[8] C. Victora, L. Adair, C. Fall et al., "Maternal and child undernutrition: consequences for adult health and human capital," The Lancet Series, vol. 371, no. 9609, pp. 340-357, 2008.

[9] D. Pelletier and E. Frongillo, "Community and international nutrition, changes in child survival are strongly associated with changes in malnutrition in developing countries," Journal of Nutrition, vol. 133, no. 1, pp. 107-119, 2003.

[10] L. M. Neufeld and S. J. Osendarp, "Global, regional and country trends in underweight and stunting as indicators of nutrition and health of populations," Nestlé Nutrition Institute Workshop Series, vol. 78, pp. 11-19, 2014.

[11] A. Dangour and R. Uauy, "Nutrition challenges for the twenty-first century," British Journal of Nutrition, vol. 96, no. 1, pp. S2-S7, 2006.

[12] G. F. Stefano and F. De Angelis, “Anthropometric growth pattern in Ethiopian infants and children: an evaluation based on different international growth references," Collegium Antropologicum, vol. 33, no. 3, pp. 729-734, 2009.

[13] Ethiopia CSAO, Ethiopia Mini Demographic and Health Survey 2014, Addis Ababa, Ethiopia, Ministry of Health, 2014.

[14] WHO, Nutrition for Health and Development, Protection of the Human Environment, WHO, Geneva, Switzerland, 2005.

[15] E. Lewit and N. Kerrebrock, "Population-based growth stunting," Future of Children, vol. 7, no. 2, pp. 149-156, 1997.

[16] MDH O, Mecha District Health Office Profile, in Office WH, editor, 2014/2015.

[17] D. Zelellw, B. Gebreigziabher, K. Alene, B. Negatie, and T. Kasahune, "Prevalence and associated factors of stunting among schoolchildren, in Debre Markos Town and Gozamen Woreda, Ethiopia, 2013," Journal of Nutrition \& Food Sciences, 2014.

[18] K. J. Rutstein Shea, "The DHS wealth index," DHS Comparative Reports No. 6, Calverton, MD, USA, 2004.

[19] G. Yasmin, L. Kustiyah, and C. Dwiriani, "Risk factors of stunting among school-aged children from eight provinces in Indonesia," Pakistan Journal of Nutrition, vol. 13, no. 10, pp. 557-566, 2014.

[20] N. Mikki, H. Abdul-Rahim, F. Awartani, and G. HolmboeOttesen, "Prevalence and sociodemographic correlates of stunting, underweight, and overweight among Palestinian school adolescents (13-15 years) in two major governorates in the West Bank," BMC Public Health, vol. 9, no. 1, 2009.

[21] A. Al-Saffar, "Stunting among primary-school children: a sample from Baghdad, Iraq," Eastern Mediterranean Health Journal, vol. 15, no. 2, pp. 322-329, 2009.

[22] Y. Shang, L. Tang, S. Zhou et al., "Stunting and soil-transmittedhelminth infections among school-age pupils in rural areas of southern China," Parasites \& Vectors, vol. 3, no. 1, p. 97, 2010.

[23] K. Bose, S. Bisai, and S. Mukherjee, "Anthropometric characteristics and nutritional status of rural school children," Internet Scientific Publications, vol. 2, no. 1, 2013.

[24] M. Fetuga, T. Ogunlesi, A. Adekanmb, and A. Alab, "Nutritional status of semi-urban Nigerian school children using the 2007 WHO reference population," West African Journal of Medicine, vol. 30, no. 5, pp. 331-336, 2011.

[25] Z. Herrador, L. Sordo, E. Gadisa et al., "Malnutrition and associated factors among school aged children in rural and urban settings of Fogera and Libo Kemkem Districts, Ethiopia," PLoS One, 2014.

[26] M. Wolde, Y. Berhan, and A. Chala, "Determinants of underweight, stunting and wasting among schoolchildren," BMC Public Health, vol. 15, no. 8, 2015.

[27] I. O. Senbanjo, K. A. Oshikoya, O. O. Odusanya, and O. F. Njokanma, "Prevalence of and risk factors for stunting among school children and adolescents in Abeokuta, southwest Nigeria," Journal of Health, Population and $\mathrm{Nu}$ trition, vol. 29, no. 4, pp. 364-370, 2011.

[28] Z. Mekonnen, S. Meka, A. Zeynudin, and S. Suleman, "Schistosoma mansoni infection and under nutrition among school age children in Fincha'a sugar estate, rural part of West Ethiopia," BMC Research Notes, vol. 7, no. 1, p. 763, 2014. 


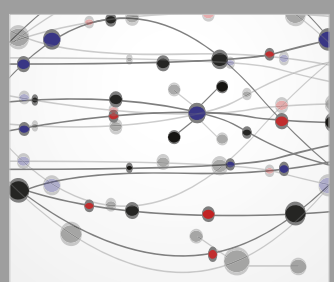

The Scientific World Journal
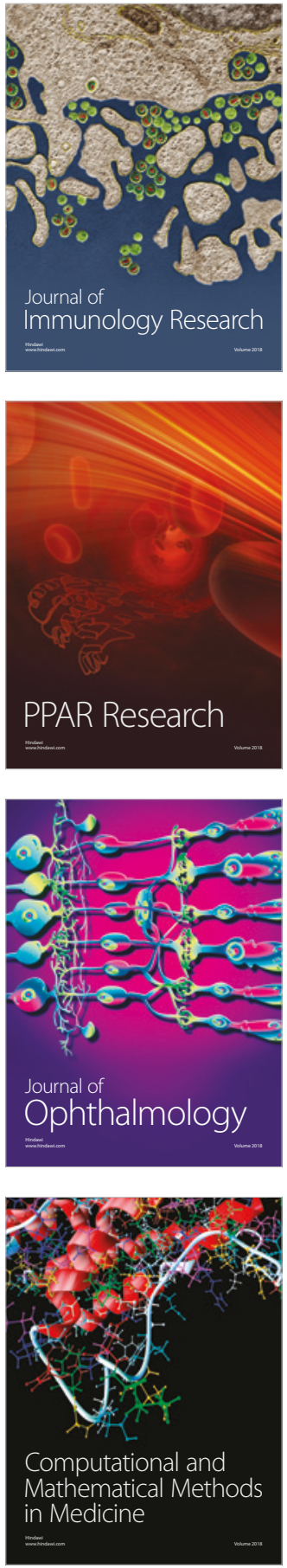

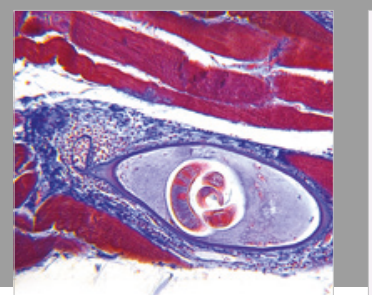

Gastroenterology Research and Practice

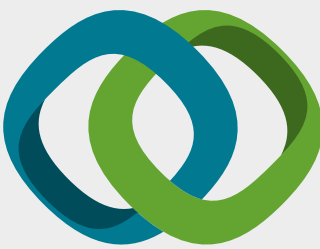

\section{Hindawi}

Submit your manuscripts at

www.hindawi.com
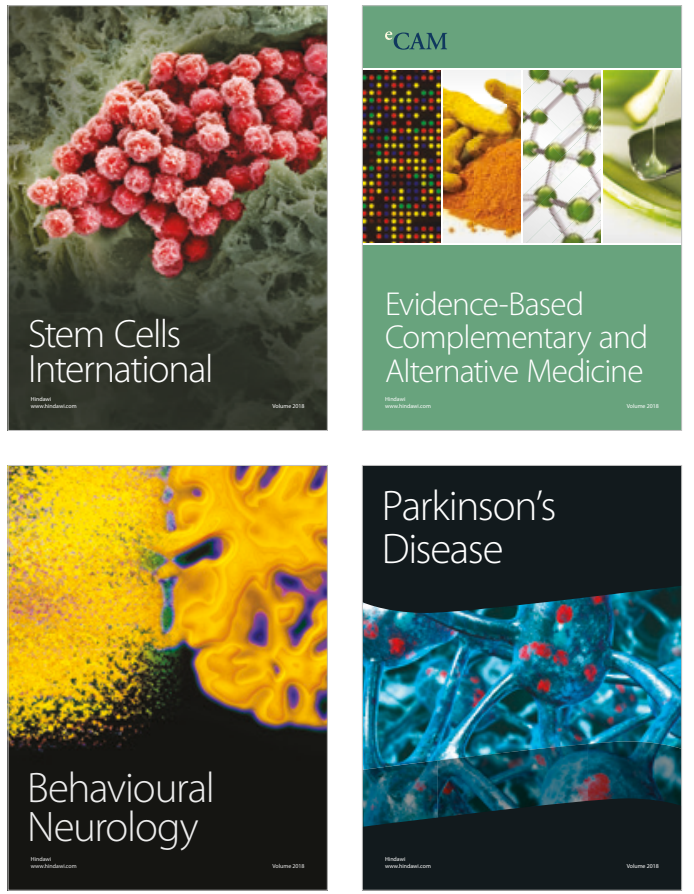

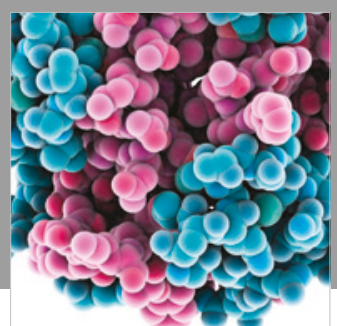

ournal of

Diabetes Research

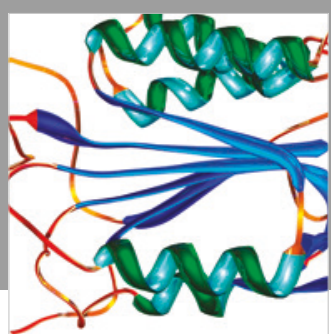

Disease Markers
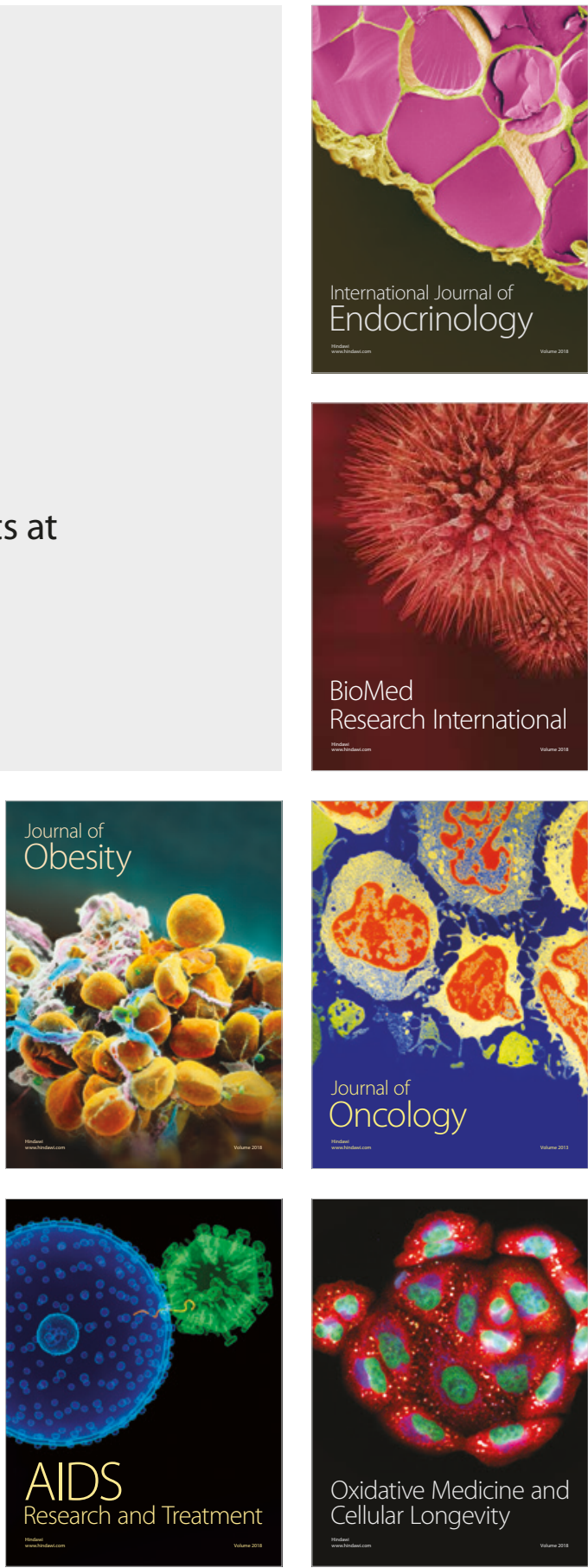